\title{
Fluid transport by cultured corneal epithelial cell layers
}

\author{
H Yang, P S Reinach, J P Koniarek, Z Wang, P Iserovich, J Fischbarg
}

\begin{abstract}
Backgroundlaims-Fluid transport across the in vitro corneal epithelium is short lived, hence difficult to detect and characterise. Since stable rates of fluid transport across several cultured epithelial cell layers have been demonstrated, the behaviour of confluent SV40 transformed rabbit corneal epithelial cells (tRCEC) grown on permeable supports was examined.

Methods-Fluid transport was determined with a nanoinjector volume clamp; the specific electrical resistance of the layers was 184 (SEM 9) $\Omega \mathrm{cm}^{2}$. tRCEC layers transported fluid (from basal to apical) against a pressure head of $3 \mathrm{~cm} \mathrm{H}_{2} \mathrm{O}$ for 2-3 hours.

Results-In the first hour, the rate of fluid transport was $5.2(0.5) \mu 1 / \mathrm{h} / \mathrm{cm}^{-2}(\mathrm{n}=23)$, which is comparable with that found in other epithelia. Fluid transport was completely inhibited in 15-30 minutes by either $100 \mu M$ ouabain $(n=6), 50 \mu M$ bumetanide $(n=6)$, or $1 \mu M$ endothelin-1 $(E T-1 ; n=6)$. Preincubation with $10 \mu M$ BQ123 (an ET $_{\mathrm{A}}$ receptor antagonist) obviated inhibition by ET-1 $(n=6)$. ET-1 also caused a $22 \%$ decrease in specific resistance.

Conclusions-Fluid transport appears to depend on transepithelial $\mathrm{Cl}^{-}$transport since (1) their directions are the same (stroma $\rightarrow$ tear), and (2) both bumetanide and ouabain inhibit it with similar time course. tRCEC appear useful to investigate aspects of the physiology and pharmacology of fluid transport across this layer, including receptor mediated control of this process.

(Br F Ophthalmol 2000;84:199-204)
\end{abstract}

For the cornea to remain transparent, it is essential that active mechanisms counter the natural tendency of the stroma to increase its hydration, swell, and opacify. It is well established that one of the corneal limiting cell layers, the corneal endothelium, transports fluid at a substantial rate, and that this transport is essential to maintain normal stromal hydration. ${ }^{1}$

As for the other limiting layer, the epithelium, in vitro measurements of rabbit corneal thinning rates have suggested that its contribution is relatively minor compared with that of the endothelium. ${ }^{2-4}$ In this connection, outward fluid movements detected in frog corneal epithelium in vitro are relatively large (a rate of $\sim 7.5 \mu \mathrm{l} / \mathrm{h} / \mathrm{cm}^{2}$ can be calculated from the data of Candia and Zamudio ${ }^{5}$ ) but are only transient ( 20 minutes). However, other evidence is consistent with transepithelial sizeable and stable water movements similar to those observed across recognised fluid transporting layers. The corneal epithelium: (1) has comparatively large osmotic permeability (88 $\left.\mu \mathrm{m} / \mathrm{s}^{6} ; 137 \mu \mathrm{m} / \mathrm{s}^{7}\right)$; (2) has also a comparatively large water diffusional permeability ${ }^{8}$ which is subject to downregulation by the removal of external $\mathrm{Cl}^{-5}$; (3) expresses functional water channels, ${ }^{89}$ which are present at a density comparable with that seen in fluid transporting layers. $^{1011}$

We report here that cultures of SV40 transformed rabbit corneal epithelial layers transport fluid from their basolateral (stromal) to their apical (tear) side at a rate which is (a) stable; (b) comparable with those measured in fluid transporting epithelia; and (c) subject to inhibition by ouabain, bumetanide, and endothelin. Our findings together with the evidence cited call for further studies to resolve why cultured cells are able to generate comparatively large and stable fluid movements whereas the corneal epithelium in vitro cannot.

\section{Materials and methods}

CELL CULTURE

SV40 transformed cultured rabbit corneal epithelial cells (tRCEC) were subcultured with Dulbecco's modified Eagle's medium (DMEM/F12) containing 6\% fetal bovine serum (FBS), insulin ( $5 \mathrm{mg} / \mathrm{ml}$ ), EGF (5 $\mathrm{ng} / \mathrm{ml})$, and gentamicin $(10 \mathrm{mg} / \mathrm{ml})$. After reaching confluence, they were passaged and cultured on treated membrane permeable inserts (Transwell, Costar, Cambridge, MA, USA; Catalogue No 3450, $24 \mathrm{~mm}$ internal diameter) at a density of $\approx 5 \times 10^{6}$ cells/insert. Cultures were maintained under $95 \%$ air- $5 \%$ carbon dioxide; every 2 days, the medium was replaced with fresh DMEM/F12 and FBS. After reaching confluence in 5-7 days, cell morphology was verified by light microscopy. Fluid transport experiments were performed 2-4 days after the layers had attained confluence.

TRANSLAYER ELECTRICAL RESISTANCE

Before an experiment, we examined by light microscopy a given confluent layer. Only layers which appeared adequate (with no obvious areas of missing cells) were used (that is, $\approx 85 \%$ of those surveyed). The integrity of these layers was further verified by measuring their specific electrical resistance. Resistance measurements were performed using a Millicell ERS chamber
Accepted for publication 9 August 1999 


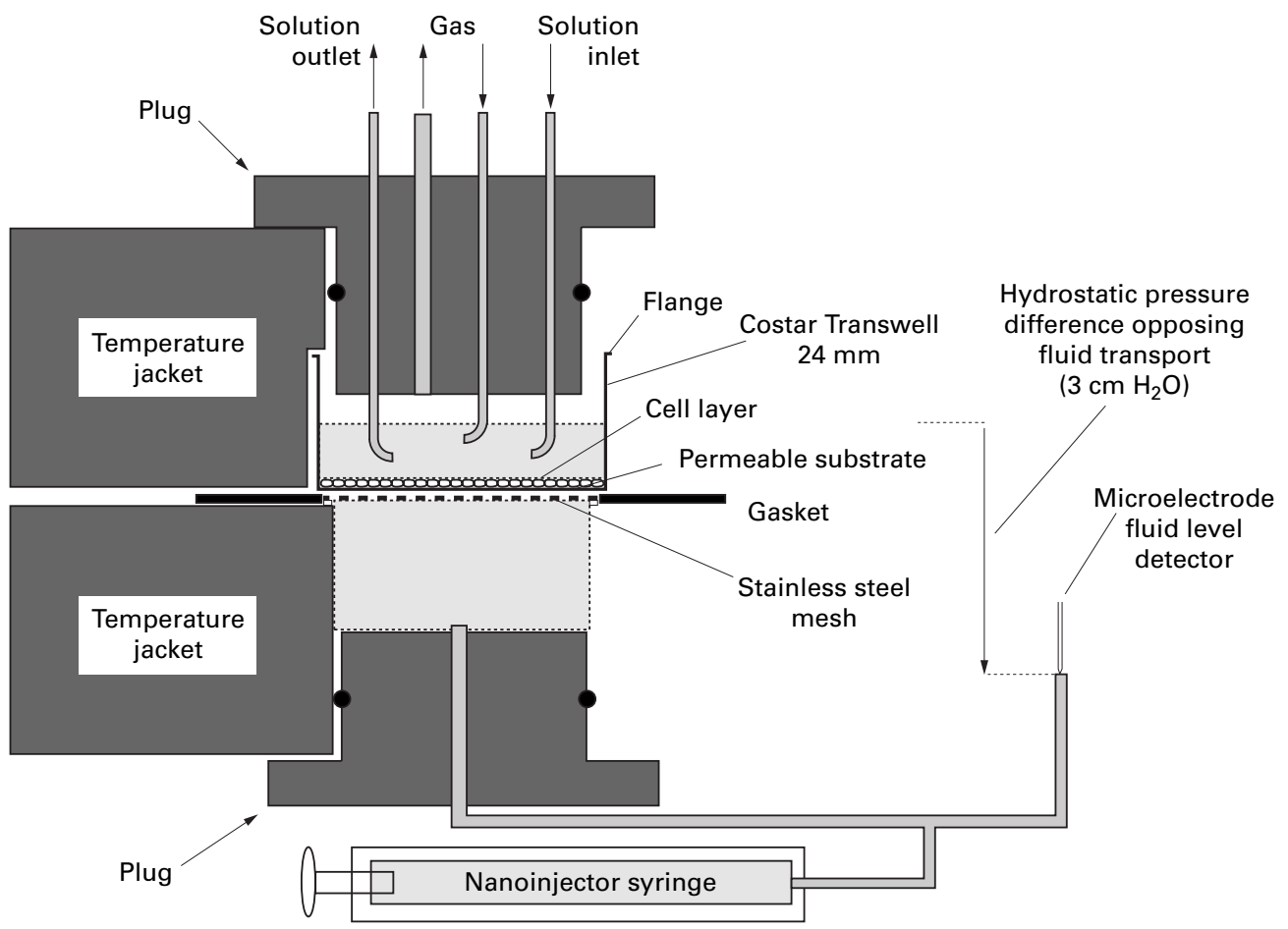

Figure 1 Schematic cross sectional diagram of the experimental setup used to measure fluid transport across epithelial cell layers ( $t R C E C)$. The right half of the chamber has been omitted so as to provide labels for the various elements within the chamber compartments.

(filled with DMEM/F12) and meter (Millipore, Bedford, MA, USA); values were corrected by subtracting the resistance of an empty insert. The translayer specific resistance was $184(\operatorname{SEM} 9) \Omega \mathrm{cm}^{2}(\mathrm{n}=23)$.

FLUID FLOW MEASUREMENTS

The rate of fluid movement across experimental preparations was determined using the Bourguet-Jard ${ }^{12}$ volume clamp method as later modified. ${ }^{13}{ }^{14}$ We utilised a chamber (see Fig 1) consisting of two halves which clamped be-

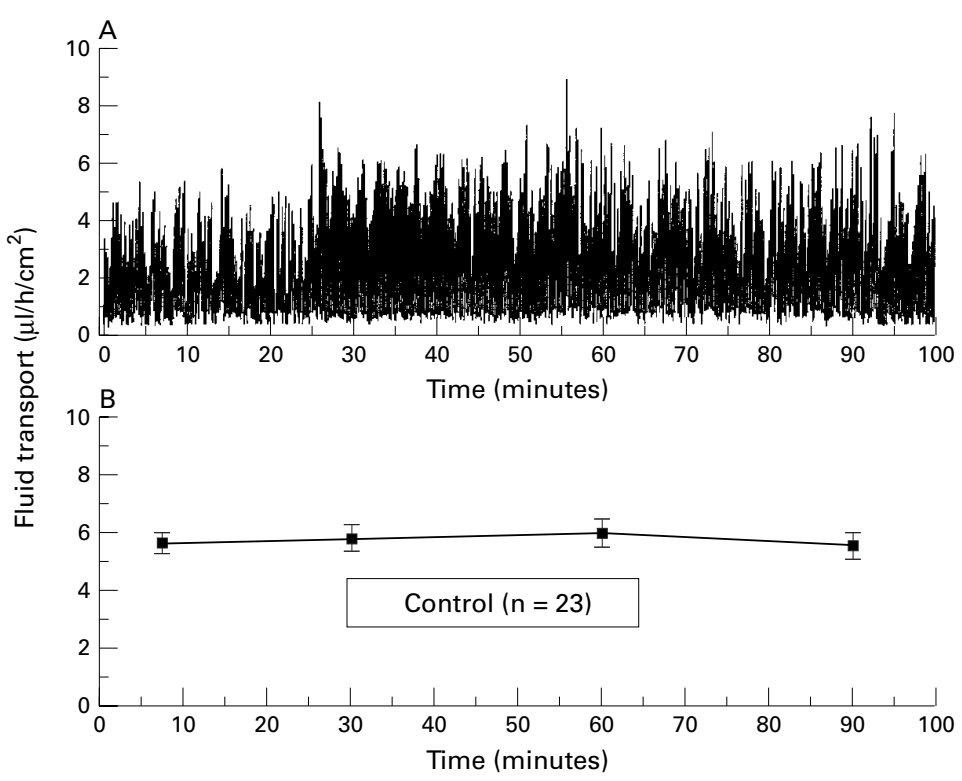

Figure 2 (A) An individual recording of fluid transport. Upward deflections correspond to fluid moving in the basolateral to apical direction, from the bottom to the upper chamber. Each deflection represents the amount of fluid transported in 12 seconds. (B) Average fluid flow recorded from 23 experiments. tween them an insert carrying a cell layer grown on a permeable support. For transparency, the chambers and their plugs were made out of Lucite; when not in use, they were immersed in water so as to prevent fluid exchange with their walls. A horizontal steel mesh disc supported the insert; the disc was covered by a fine nylon net to prevent sagging. The bottom chamber was closed to the atmosphere except for a fluid filled line connection to a fluid level sensor. Each half chamber was water jacketed for temperature control. The nanoinjector fluid flow measurement setup is similar to the one previously used by us except for its detector. ${ }^{14}$ The detection system included a glass microelectrode (microfilament glass No GCF-100-6, A-M Systems, Toledo, $\mathrm{OH}$, USA; filled with $3 \mathrm{M} \mathrm{KCl}$ ) which sensed the level of a water meniscus in a capillary tube by electrical contact. Voltage applied to the microelectrode was limited to about $100 \mathrm{mV}$ to avoid electrode blockage; an amplifier generated TTL (transistor-transistor logic) voltages to drive the nanoinjector. Evaporation from the detector's capillary represented an artefact of at most $5 \%$ of the rate of flow measured; evaporation from the upper chamber was minimal, as the chamber was closed with the plug indicated in Figure 1 except for the two 16 gauge stainless steel tubes that could serve for gassing. This setup maintained constant volume in the bottom portion of the chamber whether fluid was pumped by the tRCEC into or out of the chamber. We recorded the rate of fluid reinjected (or aspirated) into (or out of) the bottom portion; this rate directly corresponds to the rate of transport across the epithelial layer. The relative positions of the 


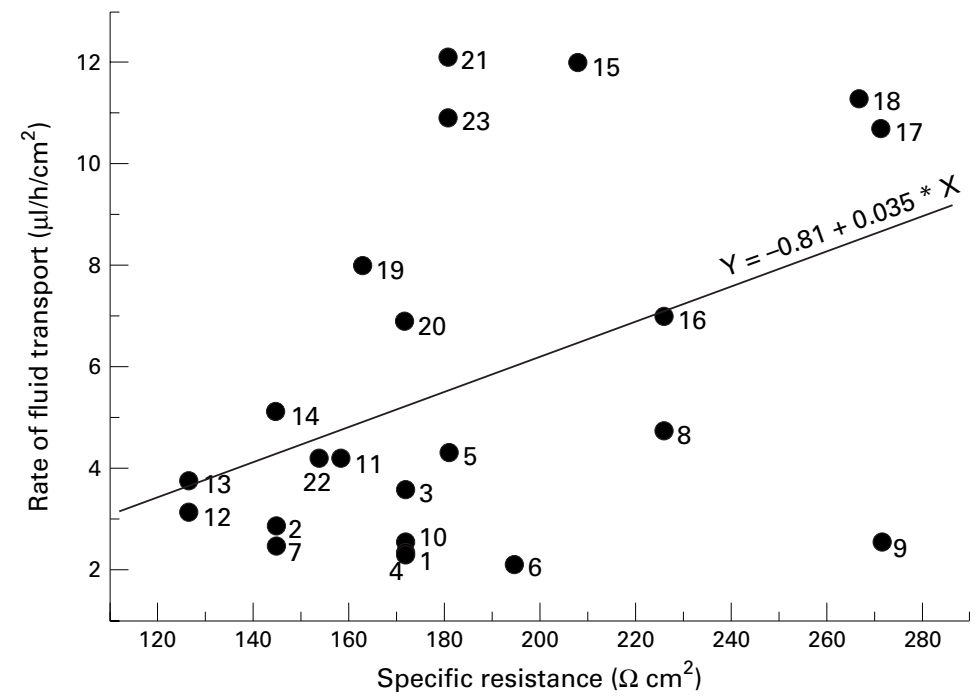

Figure 3 Relation between the rate of fluid transport and electrical resistance of the 23 cultured layers referred to in Figure 2B. Each point denotes the maximal rate for a given experiment, averaged for a period of 30 minutes; labels beside symbols denote the experiment number. A regression line fitted to the data is shown, along with its variables.

chamber and the detector were such that the hydrostatic pressure difference applied to the apical side of the cell layer (top portion of the chamber) was $3.0 \mathrm{~cm} \mathrm{H}_{2} \mathrm{O}$. Hence, when the layers transported fluid actively, they moved fluid from the bottom chamber to the top one against this hydrostatic pressure difference. The analogue output voltage from the nanoinjector was proportional to the flow rate and was fed to a chart recorder and to a computer via a DI-120 data acquisition system (Dataq Instruments, Akron, OH, USA); for data analysis, we employed the Windaq program from the same company. All experiments were performed at $37^{\circ} \mathrm{C}$. Both chamber halves were filled with DMEM/F12 plus $20 \mathrm{mM}$ HEPES, equilibrated with $95 \%$ air- $5 \%$ carbon dioxide. Once an insert was mounted, only the upper chamber was accessible for solution exchange.

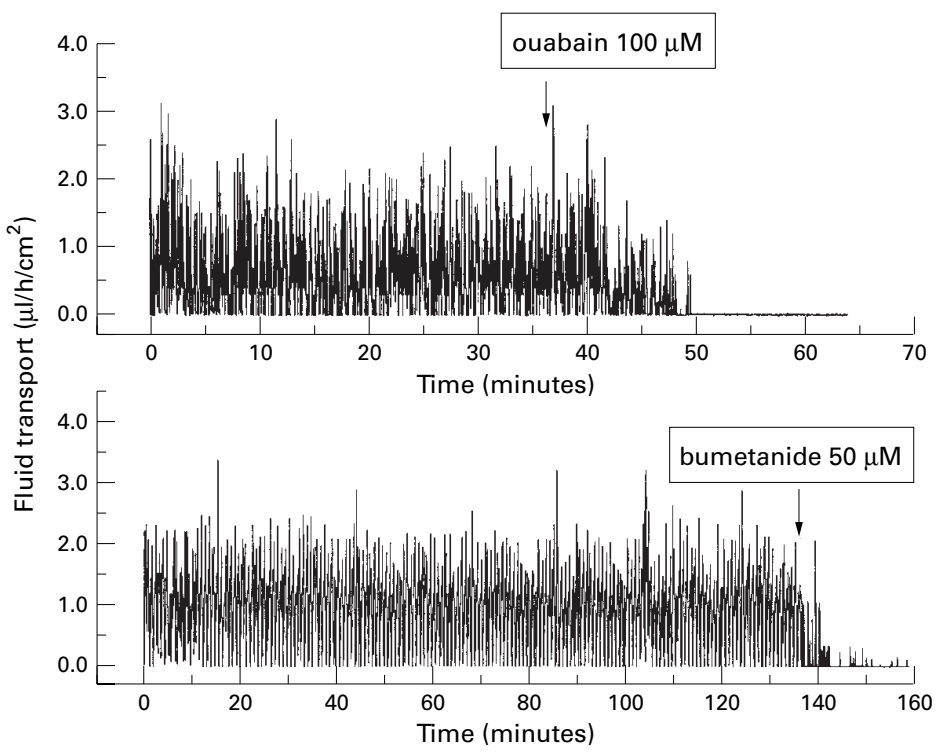

Figure 4 Recording of fluid transport as in Figure 2. Top: a representative experiment $(n=6)$, showing the inhibitory effect of $100 \mu \mathrm{M}$ ouabain added to the apical side of a cell layer. Bottom: similarly, a representative experiment $(n=6)$ showing the inhibitory effect of $50 \mu \mathrm{M}$ bumetanide ouabain added to the apical side.
Agents (ouabain, bumetanide, ET-1, BQ123) were purchased from Sigma (St Louis, MO, USA); they were introduced into the top chamber by gentle aspiration of the existing solution and replacement with a test solution. All deviations are shown as SEM.

\section{Results}

FLUID FLOW ACROSS CORNEAL EPITHELIAL

\section{LAYERS}

The results of control measurements are given in Figure 2. Figure 2A shows in detail a representative experiment. Inserts were mounted in the chamber so that the plastic support was held against the underlying net by a $3 \mathrm{~cm} \mathrm{H}_{2} \mathrm{O}$ pressure head. Under those conditions, an initial moderate leak was recorded (not shown), reflecting presumably medium temperature adjustment and settling down of the tissue onto its support. After some 15 minutes, the leak stopped, and fluid transport was observed a few minutes later. The rate of fluid transport gradually increased for 30 minutes and then remained essentially stable for the following hour. Afterwards (not shown), rates declined slowly for 90 minutes. A similar trend was observed in 23 preparations; their average rates of fluid flow are shown in Figure 2B. The longest recording period in this series was more than 4 hours.

Since the technique clamps the volume in the bottom chamber, its oxygen could not be replenished. Therefore, acidification in the bottom chamber was observed. Given these unphysiological conditions, the observed gradual decline in fluid transport could be due to loss of metabolic support for this process.

As an additional control, several experiments were terminated by puncturing the cell layer and support with a 27 gauge hypodermic needle. That procedure elicited an immediate and large leak through the preparation (not shown), suggesting that measurements obtained before puncture did indeed reflect active fluid transport by the intact layer.

Under our measurement conditions, the recorded rate of fluid transport represents the algebraic addition of fluid movement generated by the cells and a leak in the reverse direction across the paracellular pathway. Imposition of a hydrostatic pressure head across the layer is mandatory with this technique to hold the tissue immobile on its support. There is no edge damage, since the cells themselves are not clamped. Referring to Figure 1, the clamping force is exerted by the upper chamber on the upper flange of the insert, and is transmitted by the insert body down to the gasket that seals the chamber. The cells grow inside the insert, on the support up to its very limit, and thus are not affected. The magnitude of the leak is dependent on the pressure head and on the hydraulic conductance of the paracellular pathway. Since the specific electrical resistance (SER) across the layers reflects to some extent the hydraulic conductance, we recorded the initial SER in all the preparations to determine what influence (if any) the SER would have on the recorded rate. Figure 3 shows that there is a significant correlation $(r=0.43, \mathrm{p}=0.04)$ 


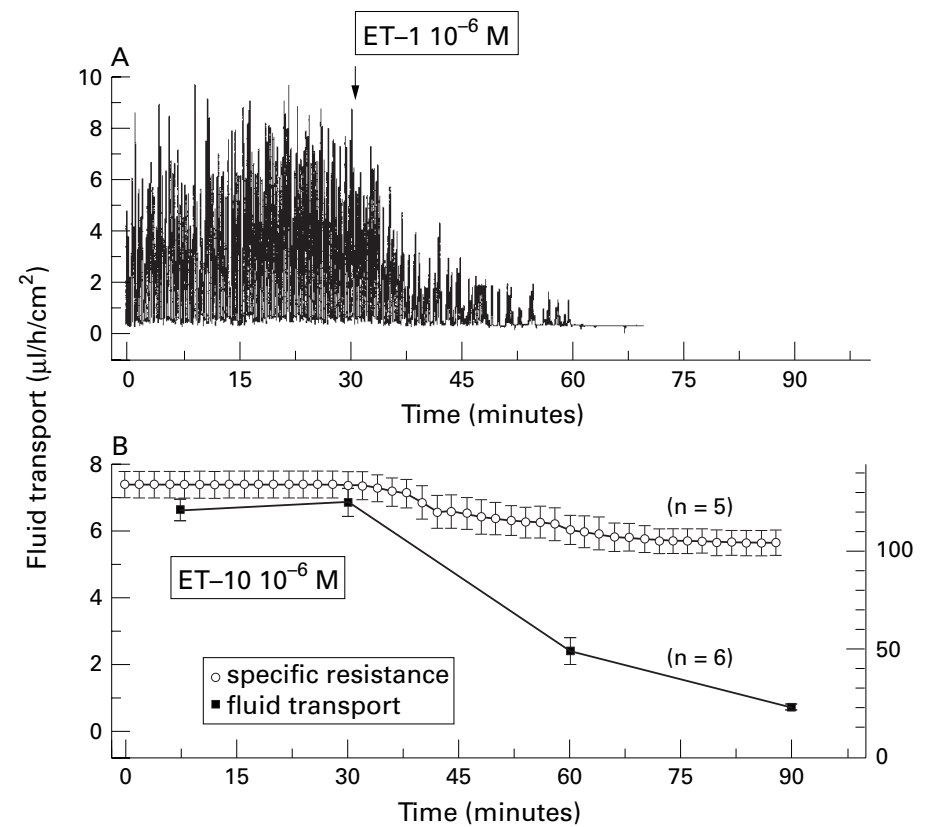

Figure 5 (A) An individual recording shows the inhibitory effect of ET-1 on fluid transport. ET-1 (final concentration: $1 \mu \mathrm{M}$ ) was added to the apical side of the cells. $(B)$ Effects of ET-1 on average rates of fluid flow $(n=6)$. This panel also shows the average specific electrical resistance of the layers before and after addition of $1 \mu M$ ET-1.

between the rate of fluid transport and the electrical resistance. It is therefore conceivable that the magnitude of the leak could partially reduce the net rate of translayer fluid movement observed under our conditions (which include the mandatory pressure head mentioned).

INHIBITORY EFFECTS OF OUABAIN AND BUMETANIDE ON FLUID TRANSPORT We determined the effects of $100 \mu \mathrm{M}$ ouabain and $50 \mu \mathrm{M}$ bumetanide. As Figure 4 shows, both inhibited fluid transport very rapidly. Ouabain inhibited fluid transport by $90 \%$ after 15 minutes, and bumetanide did likewise in some 25 minutes. Average rates of fluid transport for the preparations in these experi-

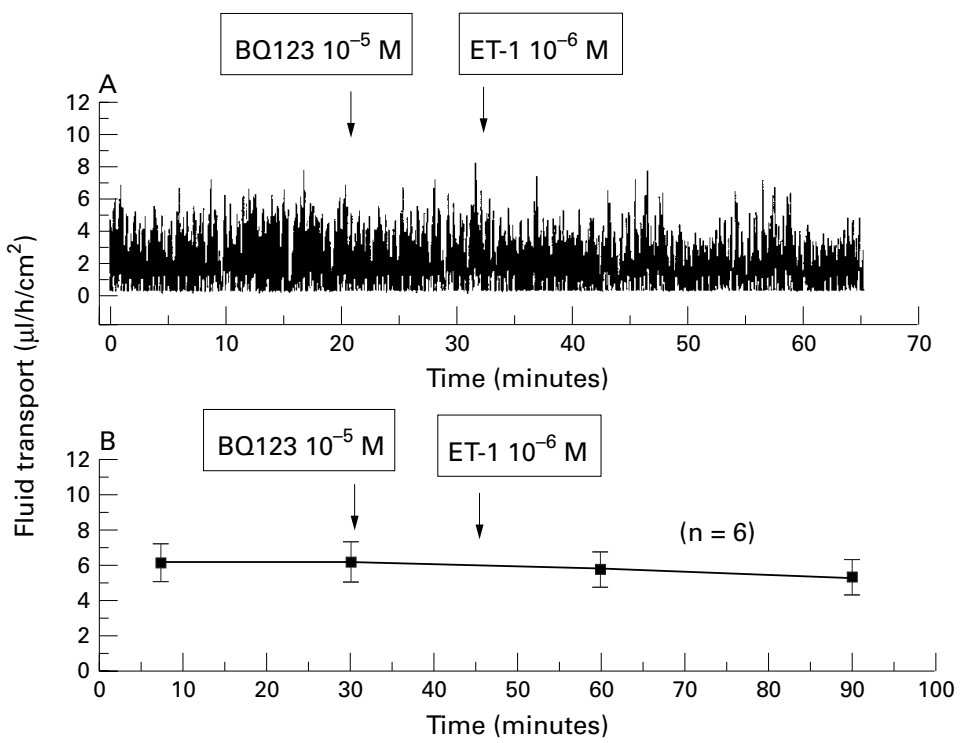

Figure 6 (A) BQ123 added to the apical side (final concentration: $10 \mu M$ ) forestalls the inhibitory effect of $1 \mu M$ ET-1. (B) Effects of BQ123 $(n=6)$. mental series during an initial control period about 1 hour were (in $\mu \mathrm{l} / \mathrm{h} / \mathrm{cm}^{2}$ ): ouabain series, $4.4(0.2)(\mathrm{n}=6)$; bumetanide series: $3.8(0.6)$ $(\mathrm{n}=6)$.

ENDOTHELIN RECEPTORS MODULATE FLUID

TRANSPORT

Having found that tRCEC transport fluid, we sought to determine whether this process could be modulated by a determinant of cellular activity, receptor linked signalling. We chose to probe for an effect triggered by the ET receptor subtype, $\mathrm{ET}_{\mathrm{A}}$, for three reasons. Firstly, one of us had reported that in cultured rabbit corneal epithelial cells, stimulation of the endothelin (ET) receptor subtype $\mathrm{ET}_{\mathrm{A}}$ with ET-1 increases phosphoinositide turnover as well as mobilises intracellular $\mathrm{Ca}^{2+}$ and stimulates adenylate cyclase activity. ${ }^{15}$ Secondly, there is expression of functional endothelin receptors in the corneal epithelium of live rabbits. ${ }^{16}$ Thirdly, the ET receptor agonist, ET-1, inhibits fluid reabsorption by rat medullary collecting ducts. ${ }^{17}$ Figure 5A depicts a typical experiment in which $10^{-6} \mathrm{M}$ ET-1 was added to the apical side bathing solution after fluid transport had stabilised at about $5.0 \mu \mathrm{l} / \mathrm{h} /$ $\mathrm{cm}^{2}$. After adding ET-1, fluid transport gradually decreased to zero over the next 60 minutes. This behaviour was observed in six experiments, as summarised in Figure 5B. As this treatment could have decreased fluid transport by increasing the paracellular leak, we determined the effect of ET-1 on the specific resistance of our cultured layers. As Figure 5A shows, $10^{-6} \mathrm{M}$ ET- 1 resulted in a $22 \%$ decrease of specific resistance during the same time period in which fluid transport was essentially eliminated. Sham additions had no such effect.

To verify that this response to ET-1 was receptor mediated, we investigated whether blocking $\mathrm{ET}_{\mathrm{A}}$ receptor activation with the selective $\mathrm{ET}_{\mathrm{A}}$ antagonist $\mathrm{BQ} 123^{18}$ could suppress the inhibitory effect of ET-1 on fluid transport. Figure 6A shows that this was the case; inhibition of $\mathrm{ET}_{\mathrm{A}}$ receptor stimulation suppressed almost completely the subsequent inhibitory effect of ET-1 on fluid transport. Average data of six experiments are shown in Figure 6B.

\section{Discussion}

FLUID TRANSPORT BY CORNEAL EPITHELIAL MONOLAYERS

Our results show for the first time that tRCEC transport fluid from their stromal (basolateral) to their tear (apical) side. The rates we report $\left(\approx 5.2 \mu \mathrm{l} / \mathrm{h} / \mathrm{cm}^{2}\right)$ are of the order of those measured across other fluid transporting layers such as the rabbit and cultured bovine corneal endothelial layers $\left(\approx 6 \mu \mathrm{l} / \mathrm{h} / \mathrm{cm}^{2}\right.$ and $4 \mu \mathrm{l} / \mathrm{h} / \mathrm{cm}^{2}$, respectively). ${ }^{11419}$

Small or transient transepithelial net fluid transport from stroma to tears (outwards) has been observed before in vitro. (a) Rates of at most $0.2 \mu \mathrm{l} / \mathrm{h} / \mathrm{cm}^{2}$ were reported in unstimulated in vitro rabbit preparations. ${ }^{2}$ (b) A later study showed that stimulated rabbit preparations exhibited higher rates of fluid flow (in $\mu \mathrm{l} / \mathrm{h} / \mathrm{cm}^{2}: 1.3$ in the presence of theophylline, 4 
with $\mathrm{Cl}^{-}$free medium in the tear side, and 6 with theophylline and $\mathrm{Cl}^{-}$free together ${ }^{3}$ ). (c) Lastly, using in vitro frog cornea, a transient (20 minutes) but sizeable initial rate of fluid flow has been reported $\left(\sim 7.5 \mu \mathrm{l} / \mathrm{h} / \mathrm{cm}^{2}\right) .^{5}$ Outwards transepithelial net fluid transport has also been reported in human subjects. ${ }^{20}$ In this last study, corneal swelling was induced by hypoxia, and upon subsequent reoxygenation, thinning ensued; the authors calculated that the epithelial contribution to deturgescence amounted to as much as $80 \%$, while the endothelium contributed the remaining $20 \%$. They attributed transepithelial fluid flow to osmosis secondary to evaporation induced tear hypertonicity. In a later study, they raised doubts as to whether different degrees of ambient humidity (leading to different rates of evaporation) can affect corneal hydration. ${ }^{21}$ Since these results could alternatively be explained in part by transepithelial outwards fluid transport, additional clarification is required.

Against the background of these reports, we show here that cultured corneal epithelial cells transport fluid in sizeable amounts (5.2 $\mu \mathrm{l} / \mathrm{h} / \mathrm{cm}^{2}$ ) and for extended periods of time (several hours). Ours and earlier results prompt the question: could epithelial fluid transport contribute to deturgescence in vivo more than realised so far? Although this question cannot be answered at present, we point out that in vitro corneal epithelial preparations have lost innervation, and there is evidence that $^{22}$ corneal sympathetic innervation influences membrane and receptor properties.

A clinical axiom maintains that endothelial damage has worse consequences for corneal hydration than comparable epithelial damage. At first sight, this might seem to support the view that fluid transport by the epithelium in vivo is rather small, as in some of the literature above. However, apparently this matter has not been precisely quantified. Furthermore, it is a common observation that in vitro rabbit corneas denuded from epithelium and exposed to saline on the outside swell precipitously. Perhaps the oily layer of the tears might have a role in retarding fluid inflow into the stroma across damaged areas of the epithelium. In any case, this does not appear to be a solid argument against sizeable transepithelial fluid transport.

The translayer specific electrical resistance of our cultured cell layers $\left(184 \Omega \mathrm{cm}^{2}\right)$ is low compared with that of isolated in vitro layers $\left(\sim 3 \mathrm{k} \Omega \mathrm{cm}^{2}\right) .^{2}$ Therefore, it may be perfunctorily argued that the associated high paracellular conductance across these cultured cell layers could induce higher rates of fluid transport than would develop across a tighter layer. However, the available evidence militates against such argument. (1) In the choroid plexus, cultured layers with a specific resistance of $1.7 \mathrm{k} \Omega \mathrm{cm}^{2}$ which is similar to that of in vitro rabbit corneal epithelia, exhibited fluid transport at a rate of $4.2 \mu \mathrm{l} / \mathrm{h} / \mathrm{cm}^{2}$, a rate quite comparable to those reported here. ${ }^{23}$ (2) As mentioned above, the frog corneal epithelium in vitro has a specific resistance of about $1 \mathrm{k} \Omega$ $\mathrm{cm}^{224}$ and transports fluid transiently at a rate of $\sim 7.5 \mu \mathrm{l} / \mathrm{h} / \mathrm{cm}^{2}$.

To reinforce what was stated in the introduction, we note that all the functional elements known to be required for fluid transport are present in the epithelium. They include: (1) expression of $\mathrm{AQP} 5^{89}$; (2) the demonstrated net $\mathrm{Cl}^{-}$secretion ${ }^{24}$ in the same direction as fluid transport; (3) transporters $\left(\mathrm{Na}^{+}\right.$pump and $\mathrm{Na}^{+}-\mathrm{K}^{+}-2 \mathrm{Cl}^{-}$cotransporter) involved in $\mathrm{Cl}^{-}$ secretion. ${ }^{22}{ }^{24}$ Consistent with these findings, we report here that the sizeable and stable fluid transport that we observe is inhibited by ouabain and by bumetanide. Either one of these also inhibits $\mathrm{Cl}^{-}$transport across in vitro rabbit corneal epithelium. ${ }^{22} 25$

\section{INHIBITION OF FLUID TRANSPORT BY} ENDOTHELIN

As shown in Figure 5, $10^{-6} \mathrm{M}$ ET-1 inhibits fluid transport. It is also known that this compound inhibits net $\mathrm{Cl}^{-}$transport across the cortical collecting duct. ${ }^{26}$ Since in our case both ouabain and bumetanide inhibit fluid transport (Fig 4), ET-1 inhibition of $\mathrm{Cl}^{-}$transport might account for the inhibition of fluid transport seen in Figure 5. Furthermore, ET-1 exposure results in a decline in translayer specific resistance (Fig 5A); this could reflect cell shrinkage secondary to inhibition of a $\mathrm{Cl}^{-}$uptake route such as the $\mathrm{Na}^{+}-\mathrm{K}^{+}-2 \mathrm{Cl}^{-}$cotransporter.

Finally, it is known that ET-1 can be secreted by the corneal epithelium and neighbouring tissues into the tears. ${ }^{27}{ }^{28}$ Therefore, it is conceivable that endothelin may modulate the postulated transepithelial fluid transport in vivo.

This work was supported by USPHS grants EY04795 (PSR), EY06178 (JF), and by Research to Prevent Blindness, New York, USA.

1 Maurice DM. The location of the fluid pump in the cornea. f Physiol (Lond) 1972;221:43-54.

2 Klyce SD. Transport of $\mathrm{Na}, \mathrm{Cl}$, and water by the rabbit corKlyce SD. Transport of Na, Cl, and water by the rabbit cor-
neal epithelium at resting potential. Am $\mathcal{F}$ Physiol 1975;228: 1446-52.

3 Klyce SD. Enhancing fluid secretion by the corneal epithelium. Invest Ophthalmol Vis Sci 1977;16:968-73.

4 Candia, $\mathrm{OA}$. Fluid and $\mathrm{Cl}$ transport by the epithelium of the isolated frog cornea. Fedn Proc 1976;35:703.

5 Candia OA, Zamudio AC. Chloride-activated water permeability in the frog corneal epithelium. $\mathcal{F}$ Membr Biol 1995;143:259-66.

6 Mishima S, Hedbys BO. The permeability of the corneal epithelium and endothelium to water. Exp Eye Res 1967;6: $10-32$.

7 Fischbarg J, Montoreano R. Osmotic permeabilities across corneal endothelium and antiduretic hormone-stimulated toad urinary bladder structures. Biochim Biophys Acta 1982;690:204-7.

8 Horwich T, lbarra C, Ford P, et al. mRNA from frog corneal epithelium increases water permeability in Xenopus epithelium increases water permeability in X

9 Kang F, Kuang K, Li J, et al. Cultured bovine corneal epithelial cells express a functional AQP5 water channel. Invest Ophthalmol Vis Sci 1999;40:253-7.

10 Raina S, Preston GM, Guggino WP, et al. Molecular cloning and characterization of an aquaporin cDNA from salivary, lacrimal and respiratory tissues. F Biol Chem 1995;270: 1908-12.

1 Echevarría M, Kuang K, Iserovich P, et al. Cultured bovine corneal endothelial cells express CHIP28 water channels. Am F Physiol 1993;265:C1349-55.

12 Bourguet J, Jard S. Un depositif automatique d' enregistrement du flux net d'eau à travers la peau et la vessie des amphibiens. Biochim Biophys Acta 1964;88:442-4.

13 Fischbarg J, Lim JJ, Bourguet J. Adenosine stimulation of fluid transport across rabbit corneal endothelium. $\mathcal{f} \mathrm{Memb}$ Biol 1977;35:95-112.

14 Narula P, Xu M, Kuang K, et al. Fluid transport across cultured bovine corneal endothelial cell monolayers. Am $\mathcal{F}$ Physiol 1992;262:C98-103. 
15 Takagi H, Reinach PS, Tachado SD, et al. Endothelinmediated cell signaling and proliferation in cultured rabbit corneal epithelial cells. Invest Ophthalmol Vis Sci 1994;35. 134-42.

16 Takagi H, Reinach PS, Yoshimura N, et al. Endothelin-1 promotes corneal wound healing in rabbits. Curr Eye Res 1994 13:625-8.

17 Oishi R, Nonoguchi H, Tomita K, et al. Endothelin-1 inhibits AVP-stimulated osmotic water permeability in rat inner medullary collecting duct. Am $\mathcal{f}$ Physiol 1991;261:F951-6.

18 Williams DL Jr, Jones KL, Alves K, et al. Characterization of cloned human endothelin receptors. Life Sci 1993;53:40714.

19 Zhu Z, Kuang K, Kang F, et al. Platelet activating factor inhibits fluid transport by corneal endothelium. Invest Ophthalmol Vis Sci 1996;37:1899-906.

20 O'Neal MR, Polse KA. In vivo assessment of mechanisms controlling corneal hydration. Invest Ophthalmol Vis Sci 1985;26:849-56.

21 Chen SR, Polse KA, Brand RJ, et al. Humidity effects on corneal hydration. Invest Ophthalmol Vis Sci 1990;31:1282-7.
22 Klyce SD, Wong RKS. Site and mode of adrenaline action on chloride transport across the rabbit corneal epithelium. f Physiol (Lond) 1977;266:777-99.

23 Hakvoort A, Haselbach M, Galla HJ. Active transport properties of porcine choroid plexus cells in culture. Brain Res 1998;795:247-56.

24 Zadunaisky JA. Active transport of chloride in frog cornea. Am f Physiol 1966;211:506-12.

25 Bonanno JA, Klyce SD, Cragoe EJ. Mechanism of chloride uptake in rabbit corneal epithelium. Am f Physiol uptake in rabbit
1989;257:C290-6.

26 Tomita K, Nonoguchi H, Terada Y, et al. Effects of ET-1 on water and chloride transport in cortical collecting ducts of the rat. Am f Physiol 1993;264:F690-6.

27 Tao W, Wu X Liou GI, et al. Endothelin receptor-mediated $\mathrm{Ca}^{2+}$ signaling and isoform expression in bovine corneal epithelial cells. Invest Ophthalmol Vis Sci 1997;38:130-41.

28 Takashima Y, Takagi H, Takahashi $M$, et al. Endothelin protein expression in tear glands of the rabbit. Curr Eye Res 1996;15:768-73. 